\title{
Interactive cognitive artifacts for enhancing situation awareness of incident commanders in mass casualty incidents
}

\author{
Tilo Mentler ${ }^{*}$ and Michael Herczeg
}

\begin{abstract}
In mass casualty incidents, several members of Emergency Medical Services have to take actions in the field in order to cope with many injured or sick people. Incident commanders are responsible for managing operations, guiding rescue forces and applying resources appropriately under extraordinary circumstances. Data required for situation assessment, projection of developments and decision making are gathered by many different emergency physicians and paramedics. They are shared by numerous face-to-face talks, radio and phone calls as well as with the aid of paper-based forms and notepaper. While these tools and means of communication support flexible modes of operation, they often lead to deficient awareness of the situation. Due to temporal delays, poor handwriting and incomplete data, information sharing in the field is hampered, delayed and faulty. Compared to established paper-based artifacts, interactive cognitive artifacts might improve the situations by exchanging and visualizing data in real-time. However, because of users' workload and working conditions, designing mobile computer-based tools and systems for this context of use is not only a technical but also a usability challenge. Based on the results of a two-year user-centered system design project in cooperation with German Emergency Medical Services, we discuss currently used and interactive cognitive artifacts for incident commanders. Challenges and approaches for successful user interface and interaction design are described and future work is outlined.
\end{abstract}

Keywords: Cognitive artifacts, Situation awareness, Mass casualty incident, Incident command, Emergency medical services, Usability, Interaction design

\section{Introduction}

In general terms, Emergency Medical Services (EMS) are "[...] the ambulance services component that responds to the scene of a medical or surgical emergency, stabilizes the victim of a sudden illness or injury by providing emergency medical treatment at the scene and transports the patient to a medical facility for definitive treatment" [1]. With respect to this definition, regular medical transport or emergency missions with one or few patients need to be distinguished from mass casualty incidents (MCIs) with larger number of patients. While the former are accomplished on a daily basis, the latter are rare events for EMS employees. Due to an at least temporary mismatch between patients and medical staff they require adapted tactics and workflows. Standards of

\footnotetext{
* Correspondence: mentler@imis.uni-luebeck.de

Institute for Multimedia and Interactive Systems (IMIS), University of Luebeck, Ratzeburger Allee 160, D-23562 Luebeck, Germany
}

individual treatment would require too much time and too many resources. They could only be preserved to the disadvantage of many respectively in favor of few.

Incident commanders, e.g. a chief emergency physician or an ambulance incident officer, are responsible for various aspects of command and control and are under very high physical and mental load (Fig. 1). They have to prioritize tasks, apply medical and logistical resources efficiently and lead subordinated paramedics and physicians in exceptional arrangements.

For the incident commanders, "knowing what is going on around" [2] is not possible only by direct perception and interpretation of events. Usually, circumstances are too complex and too dynamic. Many important elements and processes might be out of sight, range or mind. What matters most are
Springer

(c) 2015 Mentler and Herczeg. Open Access This article is distributed under the terms of the Creative Commons Attribution 4.0 International License (http://creativecommons.org/licenses/by/4.0/), which permits unrestricted use, distribution, and reproduction in any medium, provided you give appropriate credit to the original author(s) and the source, provide a link to the Creative Commons license, and indicate if changes were made. 


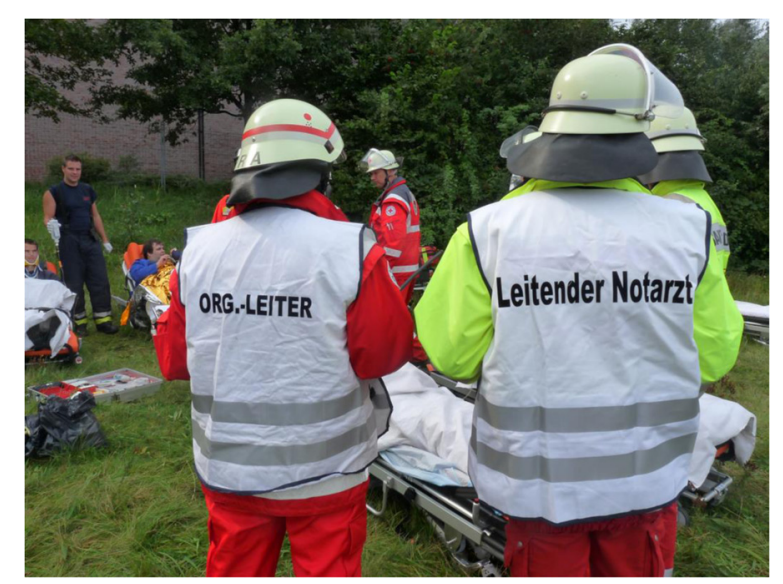

Fig. 1 Chief Emergency Physician ("Leitender Notarzt") and Ambulance Incident Officer ("Org.-Leiter") assessing the triage area during an $\mathrm{MCl}$ exercise in Germany

- a steady flow of information between incident command and operational units,

- usable tools and aids for information management.

Theses aspects represent complex challenges in preparation of and during a MCI. Domain experts and tool providers need to cooperate in order to develop practical solutions. The basic research questions of this contribution are, which cognitive artifacts are currently used by incident commanders and how interactive cognitive artifacts have to be designed in order to ease and optimize incident commanders' work.

\section{Background and related work}

In the following sections, MCIs are characterized briefly. Then the context of use is related to situation awareness and cognitive artifacts. Finally, established equipment which is currently in use by incident commanders in Germany will be described. Although national laws and local regulations might affect structures and practices of EMS in other countries, our findings can be abstracted and transferred. They are based on several actions during a two-year user-centered system design project with EMS:

- observations of two MCI exercises in different federal states;

- five workshops with EMS employees of different rescue services at which concepts and prototypes regarding the interactive system were presented and evaluated formatively;

- numerous interviews with incident commanders, emergency physicians and paramedics;

- two days of discussions with professional visitors at our booth at a large emergency trade fair.
The project resulted in an advanced prototype of an information system for managing MCIs, which has undergone formative and summative evaluations [3-5]. Related work has been conducted with respect to information exchange with maps and tactical signs in emergencies [6] and combinations of computer-based and paper-based area maps [7].

\section{Mass casualty incidents}

Train and airplane accidents or terrorist attacks often result in publicly recognized MCIs. Nevertheless, even minor events can generate "more patients at one time than locally available resources can manage using routine procedures" [8]. Contributing factors can be time of occurrence (e.g. at night), location of accident (e.g. freeway, poorly accessible areas), weather conditions (e.g. heavy rain, snow, storm), and utilization of responsible EMS (e.g. while being in charge of other events at the same time).

While all involved paramedics and emergency physicians have to adapt treatment strategies and other operating principles, incident commanders have to deal with questions of leadership and organization. Five essential task domains can be distinguished [9]:

- tactics,

- triage,

- treatment,

- taking care,

- transport.

Managing MCIs efficiently will only be possible, if operations are co-ordinated and EMS members led by superiors. Courses of action need be coordinated and a spatial order has to be established (tactics). Triage, i.e. efficiently determining severities of injuries and prioritizing treatments, is regarded to be the most important task following basic life support actions [10]. It implies an order in which casualties are transferred from triage to transport. The process should be supervised by the chief emergency physician and supported by the ambulance incident officer. Furthermore, they are responsible for organizing and running specifics areas of operation for triage, treatment and transport. A specific flow of information between the incident commanders and these operation areas is crucial for performing actions in classified order. They have to be documented as complete and comprehensible as possible. Physicians in charge at hospitals receiving victims of MCIs have to rely on these records. Furthermore, EMS employees who are still waiting for being involved should be informed about the following mission.

Treatment, i.e. medical care of ill or injured people, and taking care, i.e. crisis intervention and emergency pastoral care, need to be adapted to the circumstances. Standards and procedures of individual care would be 
too time-consuming or resource-intensive. Finally, casualties need to be taken to clinical environments for further treatments (transport).

\section{Situation awareness in $\mathrm{MCls}$}

Situation awareness (SA) can be defined as "the perception of the elements in the environment within a volume of time and space, the comprehension of their meaning, and the projection of their status in the near future" [11]. SA has been repeatedly identified as a major concern in domains like aviation, traffic control, power plant operation and defense. However, it gains increasingly importance with respect to pre-hospital medical care [12-15]. In the context of MCIs, it is both important to ensure well-arranged courses of action as well as a demanding challenge:

- Perceiving environmental elements is affected by their spatial distribution and permanent movement (e.g. arriving and departing ambulances, wandering patients and EMS employees).

- Comprehending their meaning is complicated by disturbances and various stressors (e.g. noise, number of casualties, conflicts of competence, mission lasting several hours, leaving injured people behind).

- Projecting the future is limited by suddenly changing settings (e.g. physical condition of casualties) and occupied cognitive resources (e.g. by making decisions or coordinating resources).

Tools and aids for record keeping and information management should support incident commanders' work and decrease their workload while accomplishing several unusual tasks in parallel and under time pressure.

\section{Cognitive artifacts in $\mathrm{MCls}$}

Cognitive artifacts can be defined as "artificial devices that maintain, display, or operate upon information in order to and suitable serve a representational function and that affect human cognitive performance" [16]. On different levels of abstraction they represent entities and relationships which are of peculiar interest in a specific domain [17]. With regard to MCIs, these are patients and their medical conditions as well as available medical resources (e.g. vehicles, physicians, utilization of hospitals). Some of them are locally available; others have to be requested from a distance.

Cognitive artifacts are meant to support and ease human problem solving as well as accelerate and improve task completion. However, from a personal view, introducing or modifying cognitive artifacts changes the way how people can accomplish tasks and how cooperation will be conducted [16]. Incident commanders have been skilled in different topics (e.g. emergency medicine, command and control), but they are different from operators of other complex socio-technical systems (e.g. aviation) in several respects. First of all, they do not perform supervisory control on a daily basis. Crews for regular missions consist of 2-3 persons and work together as well-matched teams side by side. Secondly, although applying sophisticated medical technologies regularly, they are not used to interactive and multimodal human-machine interfaces in everyday professional life.

Cognitive artifacts represent " $a$ meeting point [...] between an 'inner' environment, the substance and organization of the artifact itself, and an 'outer' environment, the surroundings in which it operates" [18]. In terms of EMS employees' working conditions, the latter can hardly be planned ahead because MCIs can occur anywhere and anytime. In spite of that, they are rare events for a specific incident commander (cf. [19] for an exemplary analysis of a German district). Therefore, cognitive artifacts in this safety-and time-critical domain have to be suitable for the task, self-descriptive and conform to user expectations. Learning and adaption phases have to be avoided respectively minimized. Otherwise, such artifacts might be a danger to life and health or would not be used at all.

\section{Cognitive artifacts for enhancing SA in MCls}

Currently, incident commanders mainly rely on paperbased cognitive artifacts [20, 21]. Forms and tables, maps and charts, and private notes can be distinguished and are discussed below. Because basic aspects like triage categories or crucial topics for incident commanders (e.g. number of patients still to treat), the selected examples of German EMS are comparable to the ones used in other countries [20-22]-although there is not even a nation-wide standard.

\section{Forms and tables}

Dedicated documentation and information systems have been developed in preparation for MCIs. They consist of various forms, which are suitable for certain areas or phases of a mission. While some of them are commercially available, others have been introduced by EMS on their own. Figure 2 shows a table with columns for patients' identifiers, names, triage categories and diagnoses. Most entries were added by handwriting. Identifiers were taken of triage tags and affixed to the form. As Fig. 2 depicts, there is a mismatch between row and tag sizes. It complicates clear assignments and readability. Such problems related to layout, color contrast and overall design of artifacts are no exception. 


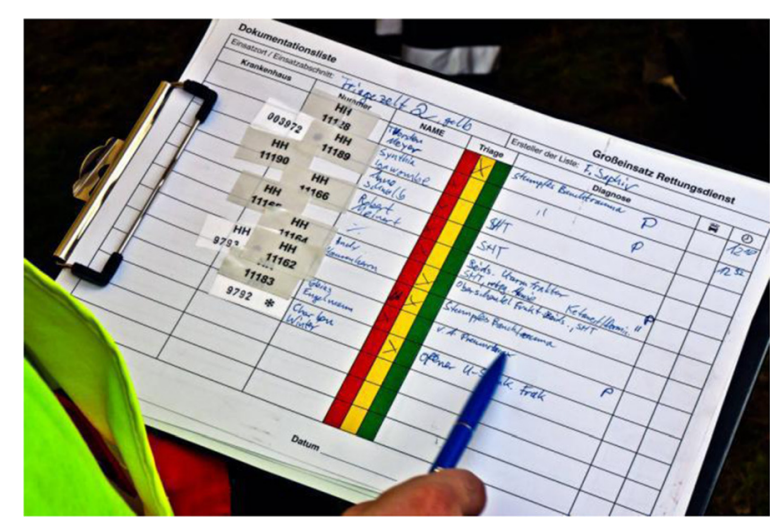

Fig. 2 Summary of patient data

Typically there will be templates for

- summarizing time and result of each patient's triage at the triage area;

- documenting actions at the treatment area(s);

- registering transport decisions at the staging area (e.g. vehicle, patient, destination, departure time);

- recording hospital assignments in order to ensure balanced distribution;

- organizing the assembly area (e.g. arrival and departure);

- enabling quality management by consolidating data from different sources.

In addition to such mainly textual and tabular representations, graphical notations are established as well.

\section{Charts and maps}

For visualizing organizational structures or spatial relations, incident commanders make use of different charts and maps. While some of them can be carried around

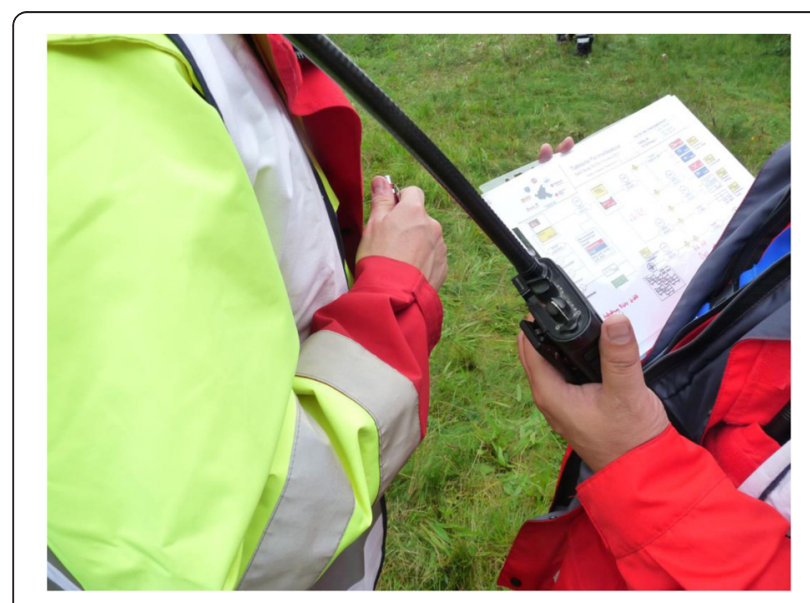

Fig. 3 Incident commander holding a chart and a radio
(Fig. 3), others are fixed at a command vehicle. Magnets or tactical signs can be applied to some of them for showing recent developments in the field. Several maps are necessary for different resolutions (e.g. vicinity, proximity, buildings) and aspects (e.g. topography, infrastructure).

Apart from using templates and published materials, many incident commanders record certain data individually.

\section{Private notes}

Some of these sheets of paper are prepared in advance, e.g. by dividing sections or listing keywords. Others are initially blank and structured on the fly (Fig. 4). Most of them are used for short-term memorization only. Sometimes they are left behind after just a few minutes of usage without referring to the notes again during or after the operation.

\section{Interactive cognitive artifacts}

While the previously mentioned artifacts can be considered to be the status quo, they will likely be replaced or complemented in the future by pervasive computerbased solutions. Advances in the development of rugged mobile devices, wireless internet access and ad-hoc networking as well as a changed perception of the overall safety situation in the western world led to increased research and development activities. Prototypes have already been tested in the field and particularly proven to work with respect to technical or infrastructural requirements like reliability of devices or data transmission in the field (e.g. [22]). Some of them process and visualize a wide range of information, e.g. patients' conditions, hospital assignments, or chronology (Fig. 5).

Questions of usability in this domain are rarely related to cognitive ergonomics, task analysis, human-computer interaction, or design (e.g. [22, 23]). Following some more general remarks to usable computer-based solutions in

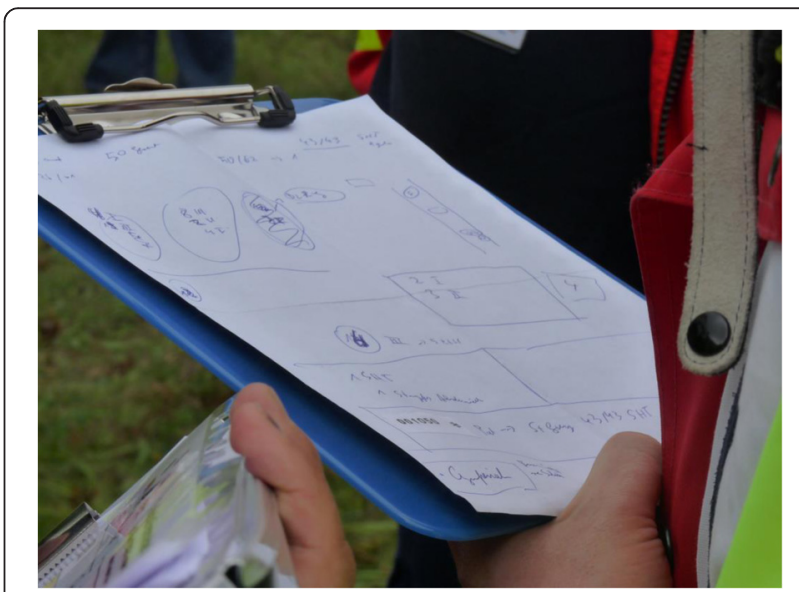

Fig. 4 Incident commander looking at notes 


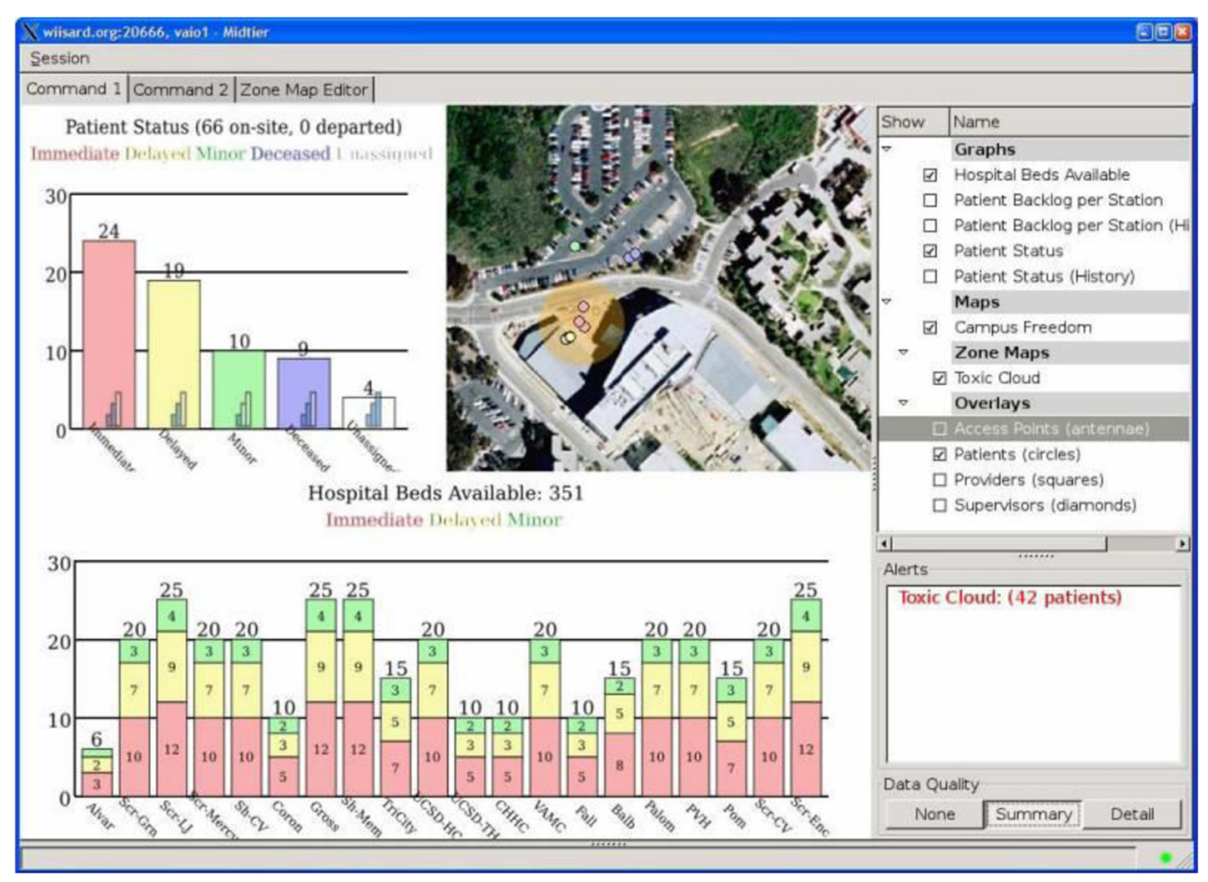

Fig. 5 The WIISARD command center display [22]

MCI management, challenges and approaches to cognitive ergonomic design of interactive tables, maps and notetaking are considered.

\section{General remarks on usability}

Developing interactive cognitive artifacts for the context of pre-hospital medical care is a challenge for various reasons. Interface and interaction should be designed iteratively and by user participation. However, short-term scheduling is complicated by work schedules and staff requirements.

Field studies and test runs can hardly be projected. Workshops, interviews and expert reviews often take place in conference facilities or office rooms. Such favorable conditions differ completely from the real context of use. Thus, natural environments, interruptions and other performance disturbing factors that characterize MCIs have to be considered specifically and carefully. What seems like an appropriate approach in a relaxed training situation might be a hardly manageable case of information overload in the field. Furthermore, computer-based tools and systems are an additional medium of communication and channel of information. They have to be aligned with established workflows and organizational structures which depend on thorough exchange of radio messages.

Practice in efficient and safe handling as well as operating interactive cognitive artifacts cannot be ensured by exercises or training courses alone. It can only be derived from intense and regular application. Because MCIs are rare events for single EMS employees, this requirement can only be met, if interactive systems will be used in daily routine and not just during MCIs. A rugged tablet PC (Fig. 6) can be considered an appropriate hardware solution for a consistent user interface designed for regular and extraordinary missions. We have basically confirmed this in formative and summative evaluations based on a prototypical application $[4,5]$.

Because of possible difficulties arising from wearing gloves, touching accidentally or working with dirty hands, pen-based interaction should be supported by the system. Losing the pen might be an additional risk but it can be minimized by fastening it with a tear-resistant but flexible ribbon. Other input methods which are supported by state-of-the-art and off-the-shelf tablet PCs, e.g. speech or gestures, have to be judged critically. One the one hand, speech input usually demands high working memory resources of users and recognition rates could drastically decrease in noisy environments like MCI settings. On the other hand, gestures have to be remembered and performed correctly. This might be challenging with respect to weather or physical conditions.

Among other aspects, consistency can be ensured or improved by using well-known and appropriate layouts, data input widgets, visualizations, feedback mechanisms, error messages, symbols and colors. Although striving for it, certain screen layouts and interaction elements, which are important to MCI management, will not be used by incident commanders in their daily duty as regular emergency physicians or paramedics. One example is the distribution of triage categories shown in 


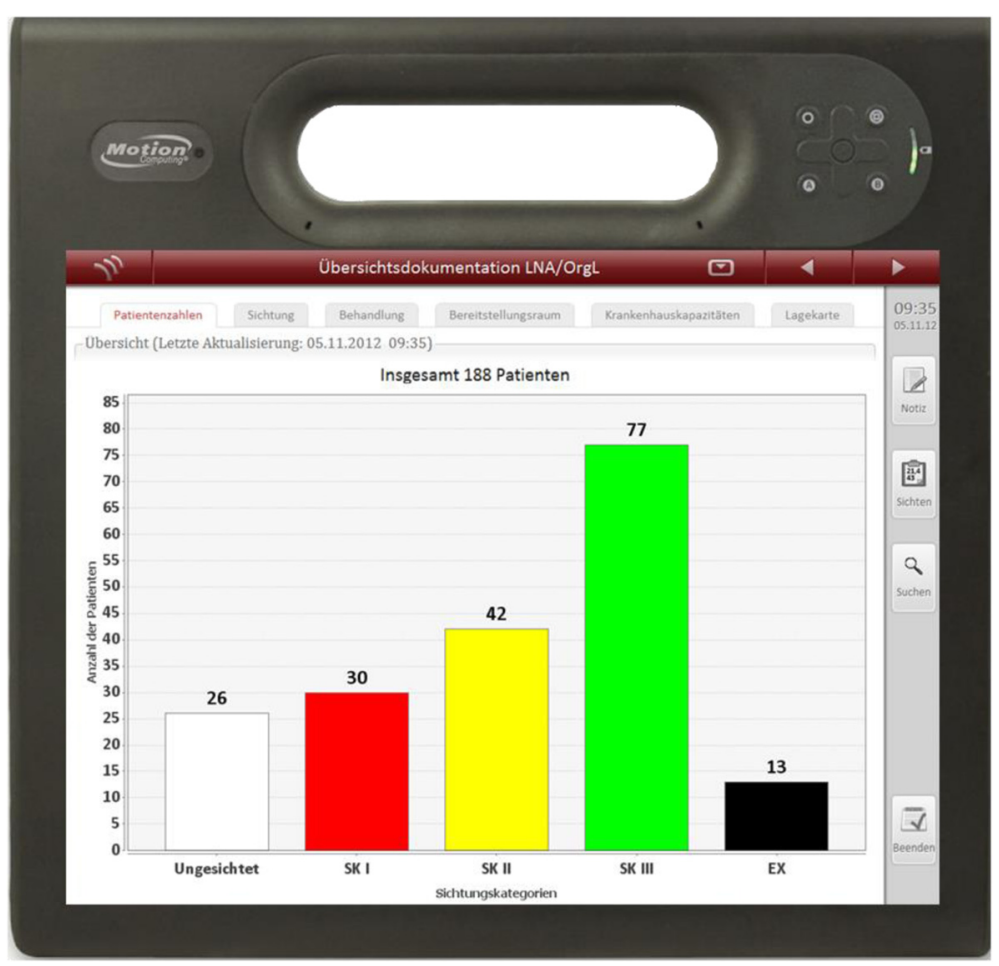

Fig. 6 Rugged tablet PC displaying the distribution of triage categories as a bar chart

Fig. 6. Especially while dealing with well-known design issues for these parts, well-established design principles (e.g. [24]) should be considered. These best practices need to be applied to the specific context of MCIs [25]. As they represent essential entities and relationships, currently used cognitive artifacts might be an appropriate starting point for this process.

In safety-and time-critical domains with highly skilled personnel, it seems advisable to build upon practical experiences. Furthermore, questions of automation, adaption, and individualization arise with respect to division of tasks between human and machine. User interfaces and interaction methods have to be designed with respect to hardware capabilities (e.g. screen size, resolution, input and output modalities) and context.

\section{Challenges and approaches to ergonomic design}

As mentioned before, incident commanders currently take private notes and work with various paper-based documents in order to enhance their SA. Some of them are stationary and others have to be delivered manually. They can be arranged, sorted, or marked by the user to a limited extent. Computer-based tools allow data access and exchange near real-time and from remote but offer only limited screen space. Feedback about incoming data must be given explicitly.

\section{Forms and tables}

With respect to forms and tables, some major challenges are

- efficient navigation between different sections;

- comprehensive visualization of larger datasets;

- fast browsing of numerous datasets.

Tabs, i.e. multiple screen masks within a single container and a navigational widget, can be used to group single tables logically and ease access. Another approach is to mark an item in one table and see links to related items in other forms. This requires efficient design solutions for backward and forward navigation, e.g. breadcrumbs.

Larger datasets might not be presentable in a single table row. Possible approaches would be folding out entries on demand or displaying detailed data of a marked entry in an overlay panel. Search options have to be available and should support phonetic search. By doing this, search results would be returned that sound similar to the given term. This might be important because incident commanders might not know correct spelling of some search terms, e.g. last names, or make typing errors while having serious time pressure. Moreover, in favor of searching by entering data freely, filter mechanisms should be implemented, if the range of values is limited. They would only offer proper values. Activated 
filters must be clearly visible, e.g. by changed background colors or other visual hints. Otherwise, the subset of displayed datasets could be perceived as the total set. Temporarily marking favorites, e.g. in terms of patients to remember, can be a feature to relieve incident commanders' working memory and allow them to continue tasks later on more easily.

With respect to browsing larger datasets, paging and continuous scrolling are basic options. While the latter one is the most prevalent at mobile devices in general, we observed some difficulties with pen-enabled devices. Some users slipped of the surface while trying to move the pen up or down. Such difficulties could increase stress levels. Therefore, we recommend implementing a more fail-safe paging solution-at least in addition to the other one. Regardless of the approach, all interaction elements should offer a sufficient target area in order to deal with pen interaction challenges like occlusion.

\section{Charts and maps}

The number of patients in specific triage category is one of the most important chunks of information for incident commanders. In addition to tabular or textual visualizations, bar charts can be an appropriate design solution. During our workshops we presented four drafts differing in the number of categories and labeling (Fig. 7) to 36 EMS employees. We asked for their favorite or a self-created version. While 2 responses were ambiguous, 34 could be evaluated. The 3 most preferred versions got 9,6 and 5 votes, respectively. 5 participants created their own solution. Allowing for minor modifications, e.g. position of labels, one version got 14 votes. The drafts were subject of controversial discussion. They enabled us to better match our conceptual model with their mental model beyond the use cases associated with the actual chart.

Using location-based services by tracking casualties, EMS employees or vehicles and visualizing them on maps looks promising but raises issues of reliability. Both tracking inaccuracies (e.g. in buildings, under bridges) and loss or removal of locatable items (e.g. by casualties in a state of shock) could result in inaccurate data. Such data would be worse than none at all. More or less stationary information (e.g. territorial allocation of operation areas) can be represented more reliable (Fig. 8).

Data exchange with geographic information systems in emergency control rooms or command vehicles might be necessary. Moreover, some incident commanders and EMS managers expressed reservations about modifying situation maps by multiple actors. They were strongly in favor of a read-only mode for co-workers in the field.

\section{Personal notes}

Personal note-taking should always be possible and could be realized easily on a pen-enabled tablet PC. A digital notepad within reach of every screen mask can be a first step. It should support both handwriting recognition and freehand drawing. Advanced solutions could offer more shortcuts, e.g. for creating tables or marking entries in different colors, or support annotations of predefined user interface components, e.g. a digital triage tag with notes about the patient.
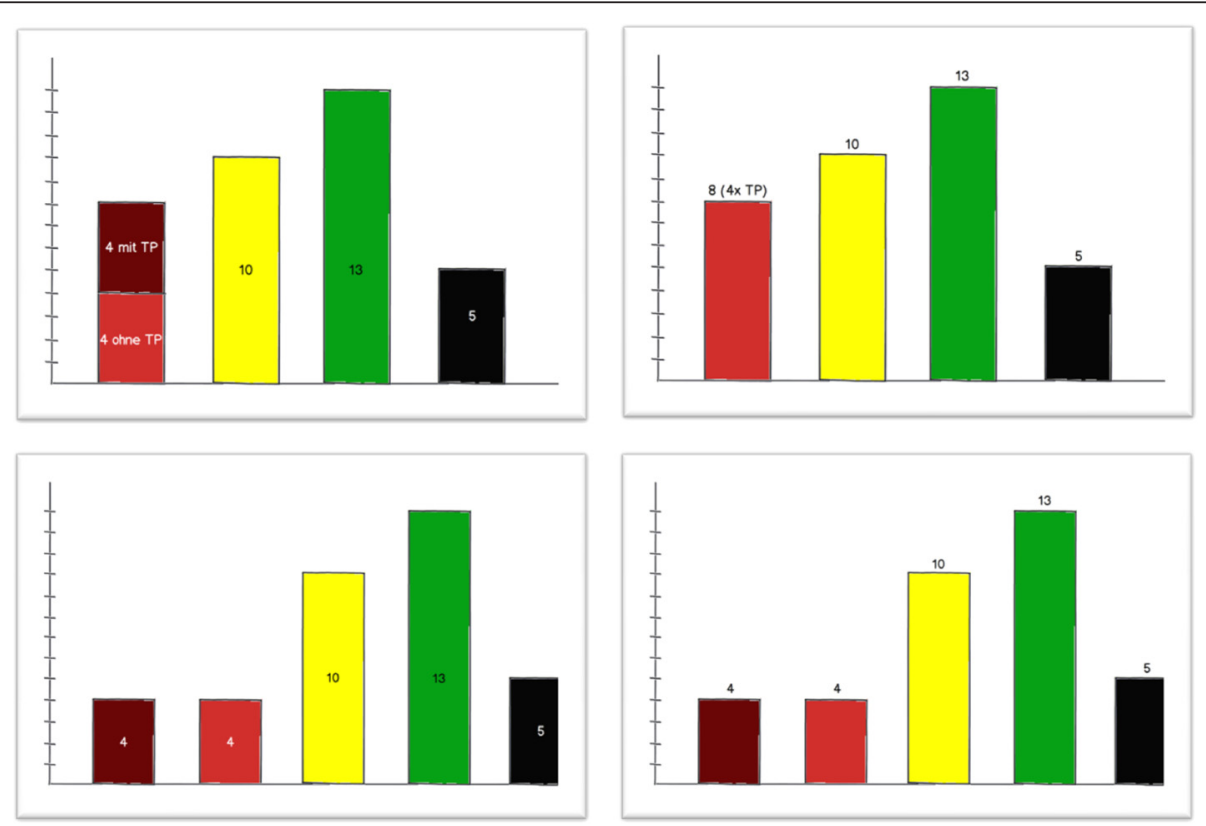

Fig. 7 Alternative designs of a triage categories bar chart 


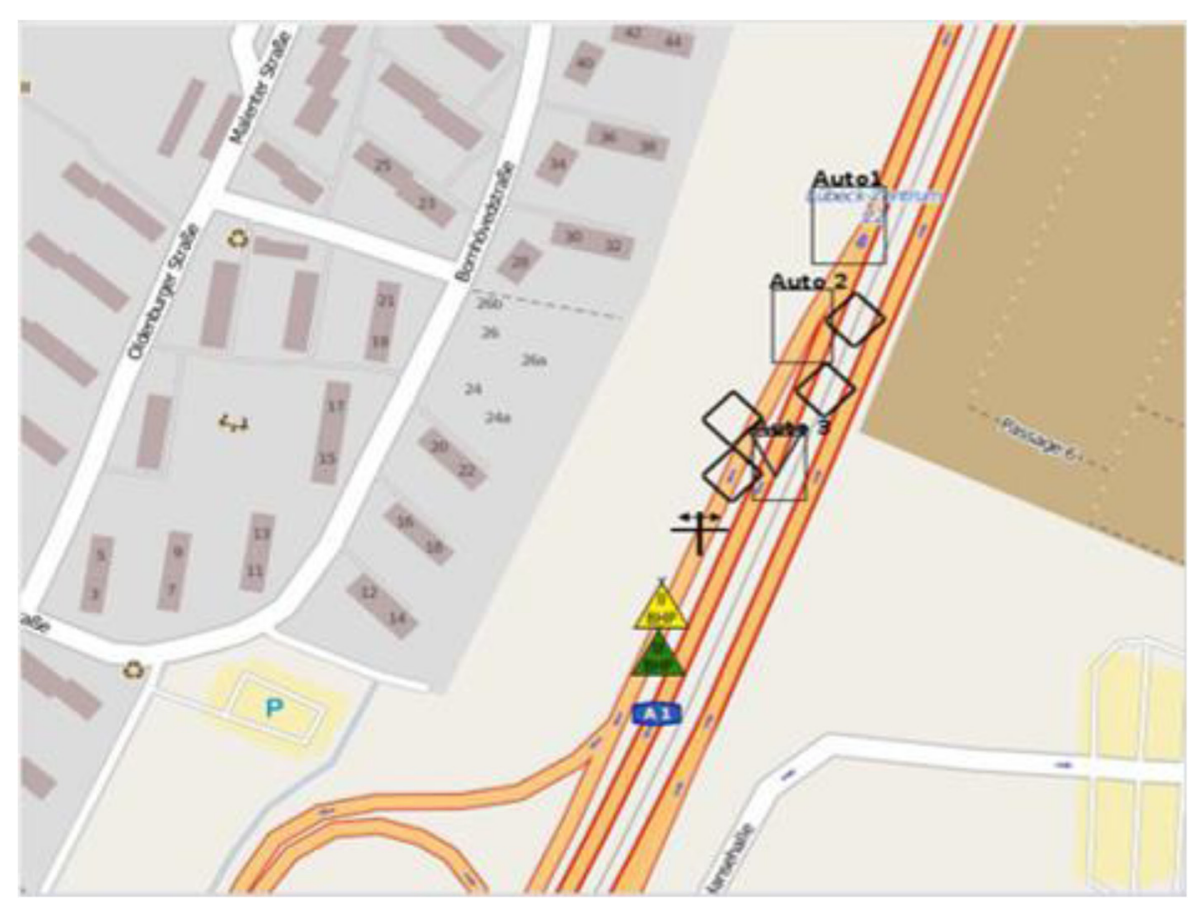

Fig. 8 Situation Map with tactical signs

\section{Conclusions}

Due to several cognitive and emotional factors, MCIs are an extraordinary challenge, even for experienced emergency physicians and paramedics. SA is of the utmost importance for incident commanders. They are responsible for best possible treatment of patients and for an acceptable workload of EMS employees. Interactive cognitive artifacts could support their demanding work and improve on established equipment. In order to achieve this, workflows and organizational structures have to be adjusted, e.g. with respect to shared situations maps or less radio messages. In any case, design and usability of these artifacts will remain an interdisciplinary challenge. Participatory design has to be conducted leading to detailed user interface and interaction design solutions like single tables or bar charts. Users might only have little time to perceive and comprehend visualizations or be disrupted meanwhile. Compatible mental, conceptual and technical models are required to minimize mental workload, ease decision-making and ensure performance in the field.

Chief Emergency Physician and Ambulance Incident Officer have to form and lead a team in order to successfully manage a MCI situation. Shared resources and requirements have to be coordinated and met with respect to their specific areas of responsibility. Therefore, future work on interactive cognitive artifacts for managing MCIs should not just consider individual SA, but Team and Shared SA as well in order to further enhance the usability of interactive cognitive artifacts and cooperation support for EMS employees [26, 27].

\section{Competing interests}

The authors declare that they have no competing interests.

\section{Authors' contributions}

All authors read and approved the final manuscript.

Received: 25 November 2014 Accepted: 21 July 2015

Published online: 19 November 2015

\section{References}

1. World Health Organization (2008). Emergency medical services systems in the European Union. http://www.euro.who.int/_data/assets/pdf_file/0003/ 114564/E92039.pdf. Accessed 09 April 2015.

2. Endsley, MR, \& Garland, DG. (2000). Situation awareness analysis and measurement. Mahwah, NJ: Lawrence Erlbaum.

3. Mentler, T, Herczeg, M (2013). Applying ISO 9241-110 dialogue principles to tablet applications in Emergency Medical Services. Proc. of 10th International ISCRAM Conference, 502-506.

4. Mentler, T, \& Herczeg, M. (2013). Routine-und Ausnahmebetrieb im mobilen Kontext des Rettungsdienstes. In S Boll, S Maaß, \& R Malaka (Eds.), Mensch \& Computer 2013 (pp. 109-118). München: Oldenbourg Verlag.

5. Mentler, T, Herczeg, M, Jent, S, Stoislow, M, \& Kindsmüller, MC. (2012). Routine Mobile Applications for Emergency Medical Services in Mass Casualty Incidents. Biomed Tech-Proceedings BMT 2012, 57(Suppl. 1), 784-787.

6. Ley, B, Ludwig, T, Pipek, V, Randall, D, Reuter, C, \& Wiedenhoefer, T. (2014). Information and Expertise Sharing in Inter-Organizational Crisis Management. Computer Supported Cooperativ Work (JCSCW), 23(4-6), 347-387.

7. Schöning, J, Rohs, M, Krüger, A, \& Stasch, C. (2009). Improving the communication of spatial information in crisis response by combining paper maps and mobile devices. In J Löffler \& M Klann (Eds.). Mobile Resp, 5424, 57-65.

8. World Health Organization (2007). Mass casualty management systemsstrategies and guidelines for building health sector capacity. http://www.who.int/ hac/techguidance/MCM_guidelines_inside_final.pdf. Accessed 09 April 2015.

9. Peter, H, \& Maurer, K. (2001). Die Leitstelle beim MANV. Wien: Stumpf + Kossendey. 
10. Peter, H, Weidringer, JW, \& Clemens-Mitschke, A. (2005). Vielzahl von Verletzten und Erkrankten. In R Lipp, K Enke, A Flemming, HP Hündorf, PG Knacke, \& P Rupp (Eds.), Berufskunde und Einsatztaktik (pp. 311-343). Wien: Stumpf + Kossendey.

11. Endsley, MR. (1995). Toward a theory of situation awareness in dynamic systems. Human Factors, 37(1), 32-64.

12. Busby, S, \& Witucki-Brown, J. (2011). Theory development for situational awareness in multi-casualty incidents. J Emerg Nurs, 37(5), 444-452.

13. Demchak, B, Chan, TC, Griswold, WG, \& Lenert, LA. (2006). Situational awareness during mass-casualty events: command and control. AMIA Symp Proc., 2006, 905.

14. Demchak, B, Griswold, WG, \& Lenert, LA. (2007). Data quality for situational awareness during mass-casualty events. AMIA Symp Proc., 2007, 176-180.

15. Jokela, J, Rådestad, M, Gryth, D, Nilsson, H, Rüter, A, Svensson, L, Harkke, V, Luoto, M, \& Castrén, M. (2012). Increased situation awareness in major incidents-radio frequency identification (RFID) technique: a promising tool. Prehosp Disaster Med, 27(1), 81-87.

16. Norman, DA. (1991). Cognitive artifacts. In JM Carroll (Ed.), Designing Interaction: Psychology at the Human-Computer Interface (pp. 17-38). Cambridge: Cambridge University Press.

17. Lee, JD, \& Kirlik, A. (2013). The Oxford Handbook of Cognitive Engineering. New York, NY: Oxford University Press.

18. Simon, H. (1996). The sciences of the artificial. Cambridge, MA: MIT Press.

19. Beck, A. (2002). Analyse der Inzidenz und Ursachen von Großschadensereignissen in einem süddeutschen Rettungsdienstbereich. Unfallchirurg, 105(11), 968-973.

20. Luiz, T, Lackner, CK, \& Peter, H (Eds.). (2010). Medizinische Gefahrenabwehr. Elsevier, Urban \& Fischer: Katastrophenmedizin und Krisenmanagement im Bevölkerungsschutz. München.

21. Crespin, UB, \& Peter, H (Eds.). (2007). Handbuch für Organisatorische Leiter Edewecht: Stumpf + Kossendey.

22. Lenert, LA, Chan, TC, Kirsh, D \& Griswold, WG (2008). Wireless internet information system for medical response in disasters (WIISARD). Final report. http://collab.nlm.nih.gov/webcastsandvideos/siirsv/ucsdsummaryreport.pdf. Accessed 09 April 2015.

23. Reuter, C, Ludwig, T, \& Pipek, V (2014). Ad Hoc participation in situation assessment: supporting mobile collaboration in emergencies. ACM Transactions on Computer-Human Interaction (ToCHI), 21(5)

24. ISO 9241-110 (2006). Ergonomics of human-system interaction-Part 110:dialogue principles. International Organization for Standardization (ISO).

25. Kindsmüller, MC, Mentler, T, Herczeg, M, \& Rumland, T (2011). Care \& prepare-usability engineering for mass casualty incidents. Proceedings of the 1st International Workshop on Engineering Interactive Computing Systems for Medicine and Health Care (EICS4Med 2011), 30-35.

26. Endsley, MR, \& Jones, WM. (2001). A model of inter-and intrateam situation awareness: Implications for design, training and measurement. In M McNeese, E Salas, \& MR Endsley (Eds.), New trends in cooperative activities: Understanding system dynamics in complex environments (pp. 46-67). Sana Monica, CA: Human Factors and Ergonomics Society.

27. Heard, J, Thakur, S, Losego, J, \& Galluppi, K. (2014). Big Board: Teleconferencing Over Maps for Shared Situational Awareness. The Journal of Collaborative Computing (JCSCW): Computer Supported Cooperative Work.

\section{Submit your manuscript to a SpringerOpen ${ }^{\circ}$ journal and benefit from:}

- Convenient online submission

- Rigorous peer review

- Immediate publication on acceptance

- Open access: articles freely available online

- High visibility within the field

- Retaining the copyright to your article

Submit your next manuscript at $\gg$ springeropen.com 